\title{
Camilo Castelo Branco e Machado de Assis NAS PÁGINAS DE $O$ FUTURO
}

\section{Camilo Castelo Branco and Machado de Assis in the pages of $O$ Futuro}

\author{
Marcelo Sandmann*
}

\begin{abstract}
RESUMO
Entre 15 de setembro de 1862 e $1^{\circ}$ de julho de 1863 , o poeta português Faustino Xavier de Novais editou, no Rio de Janeiro, o periódico literário $O$ Futuro. Nele colaboraram escritores brasileiros e portugueses, muitos destes pertencentes à colônia portuguesa da então capital do Brasil. O presente trabalho pretende investigar o espírito geral da publicação, um periódico programaticamente luso-brasileiro, com destaque para as colaborações de Machado de Assis, Camilo Castelo Branco e de seu editor, Faustino Xavier de Novais.

Palavras-chave: O Futuro; Camilo Castelo Branco; Machado de Assis; Faustino Xavier de Novais.
\end{abstract}

\begin{abstract}
Between September 15, 1862 and July 1, 1863, the Portuguese poet Faustino Xavier de Novais edited, in Rio de Janeiro, the literary magazine $O$ Futuro. In it collaborated Brazilian and Portuguese writers, many of them belonging to the then Portuguese colony of Brazil's capital. The present study aims to investigate the general spirit of the publication, a magazine programmatically Luso-Brazilian, highlighting the collaborations of Machado de Assis, Camilo Castelo Branco and its publisher, Faustino Xavier de Novais.
\end{abstract}

Keywords: O Futuro; Camilo Castelo Branco; Machado de Assis; Faustino Xavier de Novais.

* Professor Adjunto do Departamento de Linguística, Letras Clássicas e Vernáculas da UFPR, área de Literatura Portuguesa. 
São raras as referências explícitas de Machado de Assis a Camilo Castelo Branco. Em minha tese de doutorado, Aquém-além-mar: presenças portuguesas em Machado de Assis, aponto três (SANDMANN, 2004, p. 437439). As mesmas três são também lembradas em artigo de Arnaldo Saraiva, Camilo e Machado: encontros e desencontros, em que se registram ainda as três únicas da parte do primeiro em relação ao segundo (SARAIVA, 2008).

A escassez da mútua referência dá margem a indagações. Saraiva aventa a hipótese de que tal se deveria a "nobres razões de natureza estética" ou "não tão nobres razões de competitividade, emulação, despeito." (SARAIVA, 2008, p. 108). Paulo Franchetti, no artigo "Machado e Camilo", propõe duas hipóteses para o "silêncio" do brasileiro, "uma de foco externo, outra de foco interno" (FRANCHETTI, 2011, p. 5). A primeira teria em vista a polêmica em que Camilo se vê envolvido a partir da publicação do Cancioneiro alegre (1879) e as controvérsias em torno da introdução do realismo. A certa altura das transformações literárias e da própria maturação da obra de Machado, "Camilo não é autoridade a ser referida no Brasil" (FRANCHETTI, 2011, p. 6). A segunda, aquilo que, pela teorização de Harold Bloom, se denomina "angústia da influência”. Seriam muitas as aproximações possíveis em termos de fatura literária entre a obra de um e outro, e a filiação a uma tradição comum. Franchetti apresenta uma série de exemplos em que se evidenciam as "construções e os torneios sintáticos semelhantes", bem como a reiterada reflexão "sobre a ficcionalidade, o ato e os limites da escrita" e "as expectativas do leitor romântico." Muito do que reconhecemos hoje como o "estilo machadiano" estaria presente já em Camilo. Daí o "apagamento" de seu nome pelo brasileiro. (FRANCHETTI, 2011, p. 6)

Gostaria de me ater a um momento recuado na trajetória de Machado, em que tais considerações não poderiam ser postas, ao menos nesses termos. $O$ jovem escritor ainda não publicou nenhum romance, e mal iniciou-se no conto, os dois gêneros que iriam consagrá-lo. É sobretudo como poeta, cronista e autor de alguns textos críticos e pequenas peças teatrais que ele começa a ser conhecido. Por sua vez, Camilo está na sua melhor forma como novelista, às voltas com a publicação de obras como Amor de perdição, Memórias do cárcere e Coração, cabeça e estômago. E ambos estão curiosamente muito próximos, seja pelas amizades literárias em comum, seja pelo fato de compartilharem um mesmo "espaço editorial": o periódico o Futuro, um periódico programaticamente luso-brasileiro, editado pelo poeta português Faustinho Xavier de Novaes, entre 1862 e 1863, no Rio de Janeiro. Quando a publicação do periódico inicia, Machado tem cerca de 23 anos de idade; Camilo, 37; e Faustino, 42.

Nascido no Porto em 1820, Faustino havia começado nessa cidade sua carreira como escritor, colaborando em periódicos como $O$ Bardo, que 
ajudou a fundar em 1852, e outros, como Miscelânea Poética e $A$ Grinalda. Ainda em Portugal, publicou Poesias, em 1855, e Novas Poesias, em 1858, volume este precedido de um juízo crítico de Camilo Castelo Branco, de quem era amigo muito próximo. Nesse mesmo ano de 1858, mudou-se para o Rio de Janeiro com a mulher, dedicando-se ao comércio e à atividade literária, da qual a publicação de $O$ Futuro será o momento culminante. Conheceu Machado de Assis pouco tempo depois de sua chegada, provavelmente por intermédio do escritor e jornalista Augusto Emílio Zaluar, outro português radicado no Brasil. (SANDMANN, 2004, p. 75-77)

Como se lê nas páginas iniciais e finais de cada número, o Futuro apresentava-se como um "periódico literário" "colaborado por vários escritores portugueses e brasileiros", e tinha em Faustino seu "redator principal e editor responsável". Sairia regularmente nos dias $1^{\circ}$ e 15 de cada mês, entre 15 de setembro de 1862 e $1^{\circ}$ de julho de 1863 , num total de 20 números e cerca de 660 páginas somadas, quando então foi interrompido por motivos financeiros. Para pelo menos um número a cada mês, seu editor prometia a publicação de uma ilustração, promessa cumprida até o número 14. Em dois deles, são reproduzidas partituras musicais: a valsa Elvira, do pianista e compositor português Arthur Napoleão (O FUTURO, no 3 ) e a polca Esperança, de F. Moniz Barreto Jr ( $\mathrm{n}^{\circ} 8$ ). Passaram pelo periódico, incluído seu editor, 41 colaboradores ao todo, considerando-se também aqueles que assinam apenas com uma ou mais iniciais do nome, ou adotam pseudônimo, como é o caso de "Ninguém".

No primeiro número, de 15 de setembro de 1862 , lemos um texto de Reinaldo Carlos Montoro, outro escritor originário do Porto e radicado no Rio, que funciona como um manifesto de intenções da nova publicação. Intitulado Ao Público Brasileiro e Português, inicia nos seguintes termos: "Este periódico vai tentar a realização de um pensamento há muito conhecido por todos os que prezam as literaturas dos dous países em que se fala a língua portuguesa. Estabelecer um campo comum, em que livremente, sem preocupações mesquinhas de opinião ou nacionalidade, viessem discursar os escritores de ambas as nações, levar a estas o conhecimento mútuo do movimento literário de cada uma, e dar impulso com o exemplo recíproco, ao progresso literário de países tão férteis em imaginações ricas e pensadores elevados (...)" (O FUTURO, n 1, p. 25).

O periódico, de fato, congregará escritores brasileiros e portugueses, de além-mar ou da colônia portuguesa no Rio de Janeiro. Entre os portugueses, avultam aqueles que, como seu editor, são provenientes do Porto ou orbitam à roda daquela cidade. Cada número apresentará entre 5 e 8 textos, de diferente natureza: esboços biográficos; breves ensaios, que vão da literatura à economia política; impressões sobre determinado tema; 
narrativas, que podem ser contos breves ou novelas um pouco mais extensas, a demandar publicação segmentada em dois ou mais números; cartas de Portugal, com os assuntos recentes daquele país; poemas líricos, encomiásticos e satíricos; e, sempre ao final do volume, uma crônica com os assuntos da última quinzena na corte brasileira, sobretudo os literários e teatrais.

Faustino será o colaborador mais assíduo. Com exceção do número 9, assinará sempre um ou mais textos, em todos os números. No segundo, arriscará uma única vez a crônica quinzenal. No número 13, traça o "esboço biográfico" do general Manoel Jorge Rodrigues, de origem portuguesa, e figura de algum destaque na história militar brasileira. Mas é sobretudo com poemas satíricos que contribui, a par de um ou outro poema lírico ou de homenagem (A Arthur Napoleão, A Camilo Castelo Branco) e alguma prosa de teor humorístico. Por exemplo, no mesmo segundo número, insere, na sequência do poema Aspiração, de Machado de Assis, uma paródia deste, intitulada Embirração. Faustino aproveita exatamente as mesmas palavras de fim de verso do poema de Machado, para satirizar o uso do verso alexandrino, o metro de ambos os textos.

Tal uso da paródia com efeitos satíricos encontra realização de fôlego no poema Dinheiro, publicado parceladamente ao longo de 8 números do periódico. Trata-se de uma paródia das 106 oitavas do Canto I, de OS Lusíadas, a partir de expediente semelhante ao do poema Embirração. Era o início de um projeto ainda mais ambicioso, o de parodiar toda a epopéia camoniana. Faustino acabaria por limitar-se ao Canto I, numa versalhada cujo sabor pode ser sentido já na leitura da primeira estância:

\author{
Valem pouco os Baróes assinalados \\ Que, despidos na praia lusitana, \\ Por mares nunca d'antes navegados \\ A nado foram ver a Taprobana: \\ Outros heróis eu canto que, esforçados, \\ Foram pescar mais longe carne humana, \\ E palácios, depois, edificaram, \\ E seus nomes, crismados, sublimaram. \\ (O FUTURO, no 8, p. 258)
}

Entre os colaboradores que escrevem a partir de Portugal, vale destacar a Correspondência enviada por Miguel de Novaes, irmão de Faustino, com os assuntos da cidade do Porto. Ramalho Ortigão colabora com a Crônica da Literatura Portuguesa. Numa das ocasiões, faz a recensão de Memórias do cárcere, de Camilo, referindo-se ainda ao Amor de perdição, ambos recentemente publicados. José Maria de Andrade Ferreira colabora com o ensaio 
Versos de Bulhão Pato. Ana Plácido, a única mulher no periódico, publica as narrativas As Portas da Eternidade e A Desgraça da Riqueza. Antônio Feliciano de Castilho escreve uma única Carta, endereçada a Faustino, para o número 5, em que justifica a impossibilidade de colaborar com o periódico, dados os muitos compromissos.

Porém, o escritor português mais assíduo nas páginas de $O$ Futuro, depois de Faustino, é Camilo Castelo Branco. E dado o grande volume de páginas efetivamente ocupado por suas narrativas, é ele, sem dúvida, o nome mais presente no periódico.

Já no número 1, pode-se ler texto seu, intitulado O Maior Amigo de Luís de Camões. Trata-se da saborosa biografia de uma personagem fictícia, Matias Salazar, nascido no último quartel do século XVIII, filho de um professor de gramática latina, homem de poucos recursos mas grande amador das Letras. Seu pai, idólatra de Horácio e dos clássicos portugueses, sobretudo Luís de Camões, deixará de herança ao filho a ocupação de latinista, o amor pelos autores antigos e uma bela camoniana, que Salazar, a custa de muitas privações, tratará de ampliar ao longo da vida, adquirindo raridades bibliográficas. Entre alguns dos lances dignos de nota em sua trajetória, registre-se sua participação em polêmica com o Padre José Agostinho de Macedo, detrator do vate português. Em 1825, deleita-se com a publicação do Camóes, de Almeida Garrett. E, tempos depois, acompanha com muito interesse a exploração da suposta sepultura do seu adorado Camões, de cuja ossada subtrai uma vértebra, que guardará como relíquia.

No número 4, Camilo faz publicar Conhecimentos úteis. O texto, de difícil classificação, inicia com uma digressão história a respeito da cultura da lã e do algodão pelo homem, que remonta aos capítulos iniciais do Gênesis e segue até a contemporaneidade. Na parte final, o autor introduz uma breve narrativa cômica, a respeito de dois rivais que disputam o amor de uma mesma mulher. Os dois, desentendendo-se na maneira de referir-se aos encantos da dama cortejada (um diz que ela tem "peito de jaspe", ou outro diz que é "peito de algodão"), resolvem bater-se em duelo. Mas, na hora marcada para o confronto, retiram as acusações e enviam à dama "o algodão, sobreposto a uma empada de pombos em forma de coração", que a mulher comerá com regalo. (O FUTURO, nº4, p. 117)

Nos números 10 e 11, é publicada a narrativa Dous casamentos, sobre os amores de dois jovens, Guilherme e Helena. Ela é filha de um remediado professor de línguas, e ele, discípulo dileto desse mesmo professor, e filho de um algibebe falido. $O$ professor, apesar da simpatia que nutre pelo rapaz, recusa o casamento com sua filha, por serem ambos pobres, o que não daria vantagem a nenhum deles. $O$ jovem casal tem uma protetora, a Condessa de Prazins, que resolve interceder por Guilherme, um excelente co- 
nhecedor de línguas, propondo sua candidatura para uma vaga na Academia de Ciências. O jovem, porém, acaba por ser preterido, derrotado por ampla maioria de votos, e a vaga é ocupada por um poeta medíocre.

Diante do ocorrido, Guilherme toma a resolução de vir tentar a vida no Rio de Janeiro, seguindo a trajetória de tantos portugueses àquela roda. Algum tempo depois adoece, e se muda para São Paulo, onde acredita encontrar melhor clima. Vai depois ao Paraguai ("remota província", na expressão do narrador) e em seguida ao Mato Grosso, de onde é resgatado por um patrício e recambiado à pátria.

Nesse meio tempo, dado o desencontro da correspondência entre os amantes quando Guilherme ainda se encontrava no Brasil, Helena acaba por aproximar-se de Francisco de Alpona, um jornalista amigo da Condessa de Prazins. A Condessa resolve proteger o novo casal. Ardilosamente, ela, mulher de recursos, inventa um prêmio de loteria, com o qual dota Helena para que se case com o jornalista. Prepara-se então o casamento. Mas, casualmente, Helena reencontra Guilherme no "Cais das Colunas", o local onde ambos haviam se despedido anos atrás, quando Guilherme decidiu mudar-se para o Rio. Francisco de Alpona fica ciente do ocorrido e abdica generosamente da noiva. Descobre-se então apaixonado pela Condessa, que corresponde aos seus sentimentos. Celebram-se então os "dous casamentos" (entre Guilherme e Helena, e Francisco e a Condessa), para felicidade final dos protagonistas e dos leitores da novela.

A última colaboração de Camilo para o periódico, Agulha em Palheiro, é a mais ambiciosa, uma narrativa significativamente mais longa, que será publicada, a partir do número 14 , em todos os números subsequentes até o derradeiro, o número 20. Sua publicação permanecerá incompleta, dado o súbito encerramento das atividades de $O$ Futuro.

A Dedicatória é uma ostensiva homenagem a Castilho: "Ao Poeta das Crianças, das Flores, do Amor, da Melancolia e dos Desgraçados / Ao Illm. e Exm. Sr. / Antônio Feliciano de Castilho, / honra da pátria, honra dos que o prezam e amam a pátria, / oferece / o Amigo, o Respeitador, o Discípulo mais Devedor / Camilo Castelo Branco." (O FUTURO, no 14, p. 437)

Agulha em Palheiro apresenta alguns ingredientes que encontramos nas outras narrativas de Camilo publicadas em O Futuro. Por exemplo, a convivência de personagens fictícias com outras da história literária (e mesmo política), que caracteriza O Melhor Amigo de Camóes, como se viu. Ou a dedicação ao estudo e o amor aos livros, presente nessa mesma narrativa, como de alguma forma em Dous Casamentos. E, tônica de tantas novelas camilianas, a condição humilde de um ou mais protagonistas, que precisam enfrentar as constrições da pobreza e o vexame da inferioridade social, apesar da dignidade e do talento que trazem desde o nascimento. 
Francisco Lourenço Gomes é um sapateiro, filho de sapateiro, habilidoso em seu ofício, mas também um amante das Letras. É ele o sapateiro de Bocage, a quem reverencia acima de todos os poetas vivos de seu tempo, a ponto de consertar-lhe os calçados e fornecer outros novos, quando preciso, sem qualquer custo. Com isso, chega inclusive a privar da amizade do grande poeta, e dele recebe de presente poemas que oferece a Maria Luciana, filha dum colchoeiro, tio do mesmo Francisco. Os poemas conquistam o coração da moça e propiciam o casamento entre ambos.

Depois da morte de Bocage, em 1806, Francisco continua dividindo suas atenções entre o ofício de artesão e as leituras dos autores amados. É motivo de zombaria entre alguns clientes, quando, em meio ao trabalho, é provocado a recitar versos ou discorrer sobre algum autor. Seu pai chega a admoestá-lo por isso: "Lê os teus livros no teu quarto; mas, na loja, se alguém te falar em versos, fala-lhe tu em botas. Cada qual no seu ofício." (O FUTURO, nº14, p. 441)

Francisco segue o conselho do pai e passa a cultivar o hábito da leitura apenas na intimidade do lar, tendo como ouvinte a esposa: "Ouvira ela ler todos os poetas nacionais antigos e do seu tempo, exceto José Agostinho de Macedo, que Francisco aborrecia por ter sido o detrator de Camões e o êmulo atrevido e torpe de Bocage." (O FUTURO, nº14, p. 442-443). Aos poucos, Francisco reúne uma bela biblioteca, um de seus grandes orgulhos. Muito dedicado ao trabalho, acaba por acumular capital e ampliar seus negócios, a ponto de poder empregar outros artífices em sua oficina.

Depois de alguns anos, quando já não esperava, nasce seu primeiro filho, Fernando, seguido por duas filhas. Fernando, incentivado pelo pai, descobre o gosto pelas Humanidades. Diferentemente do que havia acontecido com o outro, Fernando tem condições de seguir regularmente os estudos, a ponto de chegar à Universidade. E é aqui que irá radicar o dilema que atravessa boa parte da novela: apesar de muito cultivado e de seu pai ser agora um homem de boas posses, Fernando tem vergonha da origem humilde de sua família, de simples artesãos, e, mais que isso, sapateiros. Tendo acesso aos escalóes superiores da sociedade, viverá doravante entre o desejo de ocultar a todos a sua origem ou de voltar ao meio dos seus, abdicando das possibilidades que sua formação lhe oferece. $O$ episódio amoroso em que se vê envolvido transcorrerá em meio a esse dilema. Ao fundo, entrevemos os embates ideológicos que atravessam a sociedade portuguesa na primeira metade do séc. XIX, momento de agudas transformações. A luta entre absolutistas e liberais, a Guerra Civil, o exílio de uns e outros, as reconciliações, as traições aos ideais de partida, tudo penetra a novela e recebe consideração.

É a propósito de Agulha em Palheiro que encontramos uma daquelas raras referências explícitas de Machado a Camilo. 
Machado é o escritor brasileiro com maior número de textos publicados em $O$ Futuro e, depois de Camilo e Faustino, o principal colaborador. Só não encontramos o seu nome nos números 3 e 5 . Em todos os demais está presente, com um ou dois textos. Publicará 6 poemas ao todo e um "conto fantástico", $O$ País das Quimeras. É o autor da crônica do primeiro número, função que cede a outros nos números imediatamente seguintes, para tornar-se o cronista exclusivo dos assuntos da corte, do sexto número até o derradeiro, assinando sempre com o seu próprio nome, Machado de Assis.

Os assuntos de que trata são, quase exclusivamente, do âmbito cultural, especialmente as publicações literárias recentes e a vida teatral na corte, a par de algumas apresentações musicais. Entre os escritores brasileiros, comenta a publicação de As minas da prata, de José de Alencar; a nova edição de Memórias de um sargento de milícias, de seu falecido amigo Manuel Antônio de Almeida; e a publicação das Cartas chilenas, atribuídas a Tomás Antônio Gonzaga. Discute ainda a obra de jovens autores, como Luís Guimarães Júnior, Fagundes Varela e Bruno Seabra. Está também atento às publicações portuguesas. Detém-se, por exemplo, no poema épico D. Jaime, de Tomás Ribeiro. Destaca a peça Herança do Chanceler, bem como a publicação do $1^{\circ}$ volume de Calabar, obras de Mendes Leal. Trata também de Revelaçóes, novo livro de versos de seu amigo Augusto Emílio Zaluar, colaborador de $O$ Futuro. E comenta elogiosamente a publicação de Luz coada por ferros, de Ana Plácido.

Entre os escritores portugueses tratados encontra-se também Camilo Castelo Branco, lembrado de modo algo breve e sem maior significação. Machado refere-se a ele na crônica de 15 de janeiro de 1863, publicada no ${ }^{\circ}$ 9, logo após abordar alguns lances do conflito diplomático entre o Império do Brasil e a Grã-Bretanha, aquilo que a história registraria como a Questão Christie. Mostra-se preocupado com os desdobramentos do conflito, para então tratar do livro que deverá ser publicado no periódico:

(...) não suponho que os ingleses, em caso de ataque, tenham simpatia por coisa nenhuma. Já não é desta opinião o redator principal, que tem entre mãos um romance do Sr. Camilo Castelo Branco, matéria de um grosso volume, e que o redator pretende dar todo no Futuro, capítulo por capítulo, sem receio de bala inglesa. (...) O romance, escrito expressamente para o Futuro, e propriedade desta revista, tem por título um provérbio: Agulha em palheiro. $\mathrm{O}$ palheiro é este século e a sociedade onde o poeta escreveu; o que o poeta procura é um homem, que chega a encontrar, mais feliz nisso que o vaidoso ateniense. (O FUTURO, no 9, p. 305-306)

O Futuro não irá publicar a nova novela de Camilo na íntegra. O periódico interrompe-se em meados de 1863, por problemas financeiros. 
Sanches de Frias, biógrafo de Faustino Xavier de Novaes, registra: "Em $1^{\circ}$ de julho do ano seguinte, porém, terminava a existência dessa publicação esmerada, de que chegamos a ver alguns números, por falta de pagamento de numerosos assinantes e pelo traiçoeiro procedimento de um credor, um negociante, que se dizia protetor da empresa e amigo do empresário." (FRIAS, 1907, p. 288) Que seu editor vinha tendo problemas, ficamos sabendo já ao final do $\mathrm{n}^{\circ} 14$, quando, sob o título "Expediente", lê-se o seguinte aviso: "Aos Illms. Srs. Assinantes, cuja importância da assinatura, a Redação até hoje não tenha recebido, vai ser - desde já - suspensa a entrega deste jornal." (O FUTURO, n⿳014, p. 468)

Num artigo inserido no $\mathrm{n}^{\circ} 7$, Da Imprensa Literária no Brasil, depois de um interessante apanhado dos periódicos literários saídos no país, T. de Melo, o autor, lamentava a efemeridade de tais publicações:

(...) como explicar, de modo que satisfaça o espírito indagador dos que nos observam, esse arrefecer constante, esses desaparecimentos de cada dia no nosso jornalismo literário? Por que é que só se sustentam no terreno da publicidade as folhas comerciais e políticas? É desanimadora essa observação. (O FUTURO, nº 7, p. 221)

O Futuro, para não fugir à regra, acabaria por ter o destino de tantas publicações do gênero. Como diferencial, apresentava o projeto de criar um espaço de convívio entre escritores brasileiros e portugueses, buscando um público comum. Muitos de seus colaboradores jazem no limbo das notas de rodapé das histórias e estudos literários, quando muito. Mas compuseram um grupo significativo de animadores da vida intelectual, testemunho da viva presença portuguesa na capital do Brasil àquela altura.

\section{REFERÊNCIAS}

FRANCHETTI, Paulo. Machado e Camilo. In: CONGRESSO INTERNACIONAL DA ABRALIC, XII, 2011, UFPR, Curitiba-PR. Anais... Disponível em: <http://www.abralic.org.br/anais/cong2011/ AnaisOnline/resumos/TC0622-1.pdf>.

FRIAS, Sanches de. Memórias literárias: apreciações e críticas. Lisboa: Empresa Literária e Tipográfica, 1907.

(O) FUTURO. Rio de Janeiro: Faustino Xavier de Novais, 15 de setembro de 1862 a $1^{\circ}$ de julho de 1863. 20 números.

SANDMANN, Marcelo. Aquém-além-mar: presenças portuguesas em Machado de Assis. Tese (Doutorado em Teoria e História Literária) - Instituto de Estudos da Linguagem, UNICAMP, Campinas, 2004. 487 páginas. Disponível em: <http://www.bibliotecadigital.unicamp.br/ document/?code $=$ vtls000321444 $>$. 
SARAIVA, Arnaldo. Camilo e Machado: encontros e desencontros. Navegações, PUC Rio Grande do Sul, Universidade de Lisboa, v. 2, n. 2, p. 105-108, jul./dez. 2009. Disponível em: <http:// revistaseletronicas.pucrs.br/ojs/index.php/navegacoes/article/viewFile/6392/4658>.

Submetido em: 01/04/2013

Aceito em: 30/06/2013 